\title{
La guerra de las escuelas y la psicología: Colombia 1876*
}

War of the Schools and psychology: Colombia 1876

Recibido: diciembre 15 de 2013 | Revisado: julio 26 de 2014 | Aceptado: julio 30 de 2014

\author{
GILBERTO L. OviEDo** \\ Universidad Javeriana, Bogotá, Colombia
}

doi: 10.11144/Javeriana.upsy13-5.gepc

Para citar este artículo: Oviedo, G. L. (2014). La guerra de las Escuelas y la Psicología: Colombia 1876. Universitas Psychologica, 13(5), 2003-2013. http://dx.doi.org/10.11144/Javeriana.upsy13-5.gepc

* Artículo de investigación

** Doctor en Historia Universidad Nacional de Colombia. Psicólogo y Magister en Psicología Comunitaria Universidad Javeriana. Profesor Facultad de Psicología. E-mails: goviedo01@hotmail.com; goviedo@uniandes.edu.co

\section{RES U M EN}

La guerra de las escuelas fue una disputa político-militar por la formación espiritual de la población colombiana. El radicalismo liberal sustituyó en 1872 la educación religiosa, heredada de España, por la pedagogía pestalozziana. El conservatismo reaccionó para restablecer la espiritualidad del alma y la educación escolástica regentada por la Iglesia. Las ideas políticas sobre la mente humana fueron un lema de batalla y la educación su escenario bélico. La guerra de 1876 demostró la predilección popular por el discurso religioso y su consideración de la psique como un hecho sobrenatural entendible a la luz de la fe. Los términos del debate constituyen una valiosa pieza conceptual que reflejan la aproximación colombiana a la psicología en el siglo XIX. Palabras clave

historia de la psicología en Colombia

\section{A B S T R A C T}

The war of the schools was a political-military dispute the spiritual formation of the Colombian population. The liberal radicalism replaced religious education in 1872, inherited from Spain, by pestalozzian's pedagogy. Conservatism reacted to restore the soul and spirituality of scholastic education run by the Church. Political ideas about the human mind was a slogan of battle and your war scenario education. The War of 1876 demonstrated the popular predilection for religious discourse and consideration of the psyche as a supernatural fact understandable in the light of faith. The terms of the debate are a valuable conceptual piece, reflecting the Colombian approach to psychology in the nineteenth century.

Keywords

History of psychology in Colombia 


\section{La guerra de las Escuelas y la Psicología: Colombia 1876}

Una pregunta orienta el presente estudio sobre la historia de la psicología en Colombia: ¿Qué sucedía conceptualmente en el país en el periodo de fundación de la psicología experimental alemana, a finales del siglo XIX? La respuesta suele ser muy pesimista, pues se asume la desvinculación nacional de los asuntos epistemológicos, teóricos y científicos de la disciplina (Ardila, 1973; Peña, 1993).

Colombia fue, por ese entonces, una nación azotada por las guerras civiles y las encendidas disputas políticas alimentadas por el fanatismo. Un país en guerra difícilmente puede progresar científicamente. "Con la Guerra civil permanente todo progreso es imposible... La guerra civil es la barbarie", afirmó el presidente de Colombia (1880 a 1894), Rafael Núñez (1891/1946).

El sentido común invita a mirar con escepticismo el desarrollo intelectual del país a lo largo del periodo. Resulta necesario correr el velo de desconfianza sobre el siglo XIX colombiano, para ilustrar que en medio de la guerra civil se desarrollaron debates políticos con importantes alcances académicos. La palabra "guerra" puede ser entendida, no solo, como un escenario de muerte y destrucción, sino, como la llamaba Clawsewitz (1832/2005), una extensión o la continuidad de la política por otros medios. Las guerras pueden considerarse el camino corto que recorren los pueblos para resolver problemas fundamentales de su ordenamiento social, régimen de gobierno y formas de desarrollo orgánico, al igual que las ideas directrices para el desarrollo científico.

El presente texto expone el debate político colombiano en torno a la incorporación de la psicología moderna, en medio del camino corto de la guerra. Los partidos liberal y conservador tuvieron que dirimir posturas sobre la manera de incorporar las concepciones modernas de la mente humana para adelantar el proyecto republicano.

En el año de 1876, estalló la guerra de las escuelas, expresión de la vieja discordia bipartidista sobre la formación espiritual de la nación. Desde los orígenes de la república, tras la independencia de España en 1810, se intentó resolver una serie de preguntas dirigidas a identificar el derrotero general de la nación: ¿Cómo superar el régimen de vasallaje y esclavitud, la falta de iniciativa científica, industrial y comercial heredado de la colonia española?, ¿Cómo promover el compromiso del pueblo con la construcción del Estado y la democracia? (Jarami1lo, 1956/2001).

La formación del Estado colombiano se llevó a cabo con la mirada puesta en los países desarrollados como Francia e Inglaterra y su proyecto modernizador afianzado en el individualismo (Martínez, 2001). "Los colombianos deben persuadirse que el poderío de las naciones modernas consiste en el comercio y la industria (...); en la utilidad que cada individuo añade a la masa" (García del Río, 1829/1985, p. 113). Los partidos políticos tenían por cierto que la formación de la individualidad era el patrimonio de la nación y era indispensable impulsarla desde la gestión educadora del Estado (Jaramillo, 1956/2001).

El pensamiento ilustrado había identificado con claridad el núcleo de la formación de la individualidad: la conciencia humana. Las personas persuadidas de su capacidad voluntaria para ejercer dominio sobre sus propias facultades intelectuales y ponerlas al servicio del progreso configurarían el elemento más sólido del proceso civilizatorio. La psicología moderna, la ciencia de la conciencia, fue considerada disciplina indispensable para propiciar la presencia de individuos aptos para el ejercicio de la ciudadanía. En estos términos, se refirió el líder liberal y masón Manuel Ancizar (1851, p. III) en torno a la importancia de la disciplina, en su obra pionera Lecciones de Psicología:

Encuentro (...) mérito a la psicología ecléctica, y es el de hallar en ella la razón de todas las doctrinas sociales en materia de libertad del pensamiento, de la palabra y de la industria, la justificación plena de la propiedad y la familia, y el fundamento de los preceptos de igualdad entre las personas y naciones; prueba de que el análisis de las facultades del hombre es verdadero, puesto que los hechos psicológicos estudiados en el individuo como consecuencia del ejercicio de sus facultades, se encuentran después 
manifestados idénticamente en la sociedad como consecuencia de la naturaleza y necesidades humanas.

Ancizar (1851) y sus copartidarios liberales consideraron al individuo el átomo de la sociedad. La sumatoria de individuos ilustrados y abiertos a las iniciativas científicas e industriales daría por resultado una sociedad pujante y progresista. La conciencia humana debería ser definida con claridad, antes de ser formada desde el Estado:

La conciencia es (...) una luz de todo lo que sucede en alma, y grava en ella deliberadamente nuestras percepciones, determina nuestras pasiones y determina nuestras revoluciones y actos libres, produciendo una especie de reacción sobre las facultades todas, de cuyas funciones toma conocimiento para entregarlas después al análisis de la reflexión (...) Sin la conciencia, complemento necesario de los ejercicios del alma, nada comprenderíamos ni nos haríamos cargo de ninguna de las funciones de nuestra vida mental. (Ancizar, 1851, p. 62)

El hombre de la ilustración estaba marcado por su proclive inclinación al conocimiento del mundo, pero en especial por la comprensión del aparato psíquico, instancia encargada de gestar la actividad cognoscitiva. La capacidad de observación de la propia actividad psíquica como el funcionamiento de la percepción y la memoria o el desarrollo del pensamiento haría posible la formulación de las leyes del funcionamiento mental, de modo similar a las ciencias naturales.

La psicología moderna era objeto de interés de liberales como Ancizar (1851) por ejemplificar la racionalidad científica de su época. La mente humana era descompuesta en unidades de análisis, como la sensación, para estudiar posteriormente los dispositivos de integración entre dichos elementos sensoriales, a través de leyes como la asociación mental. Así describe Boring a la psicología, ciencia de la conciencia en su periodo fundacional:

En la década de 1870 había algo fresco y emocionante en la nueva psicología experimental que Wundt había llamada psicología fisiológica... era introspectiva porque el tema de estudio era la conciencia (...). Era sensacionista porque a través de la sensación se podía conocer la naturaleza de la conciencia (...). Era elementalista porque desde el comienzo toda concepción giraba alrededor de la química mental y parecía como si las sensaciones, imágenes y sentimientos se combinaran en los compuestos que la psicología estudia. Y era asociacionista porque la asociación es el principio más importante para [integrar] los compuestos, porque la escuela británica había demostrado cómo se pueden lograr tanto la percepción como el significado a partir de la asociación de las partes. (Boring, 1929/1992, pp. 406-407)

La psicología experimental estudiaba la conciencia con base en las ideas de la filosofía empirista y su consideración de la sensación como el átomo de la conciencia. Igualmente, se fundamentó la disciplina en los principios explicativos de fisiología de la sensación, acompañada de procesos de medición. "La nueva psicología científica del siglo XIX no era otra cosa que la fusión de esas dos psicologías: la psicología de los filósofos y la psicología sensorial de los fisiólogos, más la fisiología del cerebro (...) todas las cuales procedían de distintas regiones de la ciencia" (Boring, 1929/1992, p. 182).

La psicología experimental contenía el germen del materialismo, propio de las ciencias naturales. La disciplina consideró al ser humano como un fragmento del universo físico gobernado por las leyes de la materia, una pieza más del engranaje universal, una rueda del reloj maravilloso del orden natural. El ser humano podía ser estudiado de manera objetiva, sin atavismos religiosos o prejuicios mitológicos, pues la observación científica, el rigor del método hipotético deductivo, junto con la utilización del laboratorio permitirían adelantar el proyecto secular propio del pensamiento moderno (Boring, 1929/1992).

Las ideas de la psicología experimental sobre la mente humana se convirtieron en una invitación a los partidos políticos colombianos para tomar postura en torno a la formación espiritual del pueblo. El partido liberal se sintió identificado con la idea de incorporar las visiones modernas de la mente 
humana en el proceso de formación de la conciencia individual de la ciudadanía.

El liberalismo consideró la mente como un asunto terrenal cuya explicación debería estar ligada al estudio de la naturaleza. "Decididamente la psicología habrá de romper (...) el yugo tirano de la especulación sobre la esencia íntima del hombre (...). El hombre concreto, en relación estrecha con la historia natural, con la antropología zoológica y etnológica, ese será su objeto" (Guzmán, 1883, p. VIII).

El interés liberal por la psicología moderna tenía el propósito de desterrar la tradición colonial y su visión teocéntrica sobre los asuntos humanos. Una facción del partido liberal, denominados los radicales asumieron posturas anticlericales, cada vez más recalcitrantes, que los llevaron a criticar profusamente la herencia colonial española y a procurar sustituirla por la influencia anglosajona (Jaramillo, 1956/2001).

El partido Conservador se propuso conservar la tradición española en sus aspectos nucleares: la consideración del ser humano como creación de Dios y un orden social basado en la moral católica. La mente humana fue considerada donación divina que debería ser formada por el estamento religioso para guiarla por el sendero de la salvación eterna. Se asumió la defensa del clero y su presencia como elemento moralizador de la sociedad y del Estado. La admiración conservadora por el movimiento de la restauración francesa llevó a mirar con interés el régimen de autoridad con el que la colonia española ejerció su gobierno en América (Martínez, 2001).

\section{La guerra de las escuelas y sus motivos}

José Eustorgio Salgar, presidente de la república (1870-1872), liberal, de filiación radical, impulsó desde su gobierno la Reforma Instruccionista, propuesta dirigida a modernizar la educación pública. Los liberales radicales vieron en la población analfabetismo y dependencia ideológica de las autoridades, como párrocos y gamonales. Los censos realizados en el gobierno de Salgar arrojaron resultados lamentables:
Durante muchos años los observadores habían estimado una tasa de analfabetismo de $90 \%$. Un censo realizado en 1870 demostró que de los 563.000 niños de la nación solamente 32.000 asistían a una escuela. En los distritos rurales, escasamente tres o cuatro personas podían leer un periódico (...). En 1869 el periodista Medardo Rivas se lamentaba que (...) no valían para nada las leyes que exigían a las autoridades establecer las escuelas (Meyer Loy, 1977, pp.1-2).

La limitada cobertura educativa estuvo asociada al elitismo de las escuelas. El clero mantuvo sus privilegios en materia educativa, al igual que en la colonia. El conocimiento seguía siendo considerado una dádiva divina para los elegidos y la escolástica, el régimen de enseñanza.

Salgar, trajo en 1872 la primera misión pedagógica alemana, conformada por nueve pedagogos germanos, uno por cada estado confederado. Dichos pedagogos formaron maestros normalistas e introdujeron materiales indispensables para aplicar una vez más el método pestalozziano, el cual había sido previamente introducido en la década de 1840 (Saldarriaga, 1977; Zuluaga, 2001).

La pedagogía pestalozziana ofrecía la oportunidad de llevar a la práctica educativa las ideas de la psicología moderna, con especial énfasis en la doctrina de la sensación. Pestalozzi asumió la estimulación de los sentidos como el punto de partida y el componente central de un proceso educativo. La formación de la personalidad autónoma, se iniciaba con la libre exploración sensorial de la naturaleza y la saciedad de la curiosidad infantil. El aula de clase sería un escenario destinado a desarrollar destrezas de observación sobre las cualidades o rasgos del entorno físico. El aprendiz ordenaba el mundo a través de la clasificación de sus propiedades sensoriales.

Como ser vivo no eres otra cosa que tus cinco sentidos. De lo que se deduce que la claridad u oscuridad de tus concepciones debe (...) depender de la distancia, pequeña o grande, desde la cual todos los objetos hieren tus sentidos, es decir a ti mismo, o el punto céntrico en que tus ideas vienen a reunirse en ti (...). Todo lo que sientes en ti mismo es una intuición precisa (...). El conocimiento de la verdad 
procede en el hombre del conocimiento de sí mismo (Pestalozzi, 1826/1967, pp.138-139).

Las escuelas liberales perseguían ideales de autonomía personal y juicio crítico independiente. Los manuales educativos, de la misión pedagógica alemana, enfatizaron en la regla de oro del pestalozzismo: cosas antes que palabras (Sáenz, Saldarriaga, \& Ospina, 1997). El conocimiento originado por la actividad sensorial daba lugar a un aprendizaje exitoso acompañado de la fluidez en la memoria y el pensamiento.

La reforma instruccionista contenía el germen del constructivismo, propio de la psicología moderna. El maestro debería observar atentamente los cambios intelectuales que sufrían los niños con la edad. Los contenidos académicos deberían dosificarse, para ajustarlos a las tendencias de la evolución. La experiencia del conocimiento describía una trayectoria que se iniciaba en la temprana infancia con la captación de hechos ligados a la percepción sensorial y lentamente se desplazaba hacia las ideas abstractas, las apreciaciones universalistas y las relaciones simbólicas (Sáenz et al., 1997).

Las diferencias individuales fueron consideradas un punto de partida relevante dentro de la actividad de la enseñanza. El niño debería ser reconocido por su particularidad y su proclividad a interactuar con ciertos objetos y eventos de su entorno. Pestalozzi no cesaba en su insistencia en hacer de la escuela una extensión de los aprendizajes tempranos, llevados a cabo en el seno de la vida familiar:

La época en que principia la instrucción del niño (...) es la hora de su nacimiento. Desde el instante en que sus sentidos se hacen sensibles a las impresiones de la naturaleza, desde ese instante lo instruye la naturaleza. La vida nueva no es otra cosa que la facultad, llegada a la madurez de recibir esas impresiones [sensoriales]; ella no es otra cosa que el despertamiento de los gérmenes físicos llegados a la perfección, que van a emplear todas sus fuerzas para proseguir todo el desarrollo de su propia organización; no es otra cosa que el despertar del animal, ahora completo, que quiere y debe llegar a ser hombre. (Pestalozzi, 1826/1967, pp. 60-61)
El proceso de aprendizaje fue considerado como una actividad jalonada por el interés y la motivación estudiantil. La educación escolástica debería ser abandonada, por su carácter memorístico basado en la repetición de contenidos incomprensibles, impuestos por una autoridad religiosa. En estos términos, se pronunció el semanario oficial La Escuela Normal, de 1871, con respecto al carácter motivacional de la pedagogía pestalozziana:

[La pedagogía intuitiva] no instruye solamente al hombre: lo educa, dirigiéndose a todas sus facultades, a la vez que, para procurar su desarrollo armónico, hace marchar de frente la educación física, moral e intelectual. No atormenta a la infancia obligándola a retener lo que no comprende, o inculcándole por fuerza nociones superiores a su inteligencia; consulta sus facultades, sus inclinaciones sus apetitos, y haciendo benéficas estas diversas disposiciones, las proporciona cuando enseña. Es tal el encanto y tal la inmensa utilidad de los métodos instructivos de que es inventor [Pestalozzi], que ahorran al niño la parte enojosa y árida del estudio haciendo de éste una especie de solaz. (Sáenz et al., 1997, p. 14)

El avance en el conocimiento fue considerado una inclinación natural del ser humano. La curiosidad infantil, el juego, la exploración activa del entorno eran una muestra representativa de las ansias de saber, que deberían ser canalizadas por el proceso educativo.

La Reforma Instruccionista se orientó a "sustituir la Iglesia por la escuela, y el cura por el maestro" (Gutiérrez, 2000, p. 62). El Decreto Orgánico de Instrucción Pública de 1870 estableció la gratuidad de la educación, junto con su carácter obligatorio y la condición de neutralidad religiosa (Plata, 2001). La reducción de la influencia religiosa sobre la educación fue motivo de importantes reacciones sociales.

\section{La reacción católica-conservadora}

El partido conservador, junto al clero, protestó enérgicamente por la aplicación forzosa del régimen pestalozziano de corte anglosajón, nacido en 
el seno mismo de las sociedades protestantes. Los opositores a la Reforma Instruccionista asumieron la defensa de la tradición hispánica, con especial énfasis en lo religioso.

La idea de considerar la religión, el clero y sus seguidores laicos un pesado lastre para la modernización del país fue visto como una sentencia injusta que debería reformularse (Arboleda, 1869/1972). La tradición española debería ser evaluada con mayor justeza, pues hacía parte de la historia social, el sentimiento popular, así como de las costumbres y creencias.

El discurso conservador exaltó el orden social y el régimen de autoridad moral instalada por la colonia, a través de los valores religiosos. España le legó a sus colonias un fervor por el orden moral y por la búsqueda de redención:

Dígase lo que se quiera, la colonia nos legó pueblos constituidos sobre firmísimas bases y bien organizados en lo moral, lo social y lo civil, aunque (...) adoleciera de (...) un atraso en las ciencias y en las artes; la industria y el comercio (...) España nos dejó buenas costumbres, admirablemente constituida la familia, hábitos arraigados de respeto a la autoridad (...) un clero virtuoso, creencias morales y uniformes. (Arboleda, 1869/1972, p. 198)

El conservatismo consideró en extremo descalificadora la crítica liberal a la educación escolástica. La presencia de las comunidades religiosas y su labor evangelizadora durante el periodo colonial hizo posible la unificación del continente latinoamericano en torno al catolicismo. El idioma castellano fue considerado uno de los más importantes legados espirituales que unía de manera espontánea la mayor parte del continente. Adicionalmente, la filosofía de Santo Tomás inspiró el movimiento independentista (Carrasquilla, 1881/1961).

El liberalismo fue acusado de trastocar abruptamente siglos enteros de construcción social en torno a metas religiosas. La ideología liberal pretendía reorientar la nación, sin tomar en consideración la condición humana de una sociedad formada dentro de los parámetros del catolicismo hispánico. Así, se pronunció el Obispo Bermúdez en 1875:
Si los maestros de la escuelas públicas secularizadas omiten la enseñanza del catecismo y las prácticas religiosas (...) es el primer paso a la apostasía, es una razón más que suficiente para que el pueblo no llegue a confiarles sus hijos; de otro modo, en vez de niños dóciles y obedientes, no tendrán sino hijos rebeldes, enemigos de la Iglesia, espanto de la sociedad. (Raush, 1993, p. 116)

La tradición española introdujo, a través de la educación religiosa, un conjunto de valores sociales defendidos por el clero y el conservatismo: la caridad, la actitud de servicio al prójimo, el sentimiento de hermandad cristiana enlazada por la firme convicción de la existencia de un Dios justiciero. En ausencia de la fe en Dios y su Iglesia, el país caería dentro de la más baja condición humana y las escuelas se convertirían en "criaderos de proletarios ateos (...) sin fe positiva, sin amor al hogar doméstico" (Periódico el Tradicionista 1873, citado en Rausch, 1993, p. 127).

A lo largo de la época, se dieron múltiples llamados por parte de los padres de familia para que la educación religiosa fuera incorporada en las escuelas liberales. Un ejemplo de ello fue la carta de los padres de familia del pueblo de Sesquilé, dirigida al director de Instrucción Pública, en el año1873:

Anhelamos que nuestros hijos, pedazos de nuestro corazón, se instruyan en todos los ramos del saber humano que sea posible, pero sin descuidar (...) lo único necesario, porque al final de la jornada, aquel que se salva, sabe, y aquel que no, no sabe nada. (Raush, 1993, p. 121)

La tradición escolástica, propia de la colonia, había dejado marcada una huella profunda dentro del sentir popular. Todos los actos humanos, incluido el conocimiento, tenían su origen en el alma, donación divina. El destino de los humanos, seres animados de manera racional, era la de alcanzar la salvación eterna y la bienaventuranza espiritual.

El alma racional fue considerada la verdadera inspiradora de todos los actos pensantes. La privación de la educación religiosa representaba una 
pérdida irreparable, pues implicaba el alejamiento de las personas de Dios, su creador. La felicidad del alma humana radicaba en el encuentro espiritual con Dios. Un pueblo sin Dios y sin Iglesia fue considerado fácil presa de las falsas ideologías políticas, al igual que de las ambiciones mundanas. Así se expresó uno de los más importantes protagonistas conservadores de la guerra de las escuelas:

Luchamos por esa libertad que no nos viene de las leyes humanas, sino que tienen origen divino; que nos viene de Dios, y que sirve límite a toda autoridad (...) tenemos una pauta: la moral católica; y esa pauta se encuentra resumida en el más completo de los códigos: el decálogo. (Briceño, 1878/1947)

El conservatismo promovió la imagen del ser humano como un ser necesitado de la orientación espiritual de la Iglesia para encontrar el orden personal y social. La formación del alma requería la presencia de un mentor, que inspirado en el evangelio evitara la perdición y el pecado.

La defensa de la tradición religiosa en materia educativa estuvo acompañada por masivas campañas de catequesis en todas las parroquias del país. La rápida respuesta educativa conservadora ha sido descrita en estos términos:

Se fundaron escuelas parroquiales en los cuales se enseñaba la doctrina del padre Astete, lectura y escritura, gramática, aritmética y geografía, formando así un aparato educativo alterno, del cual el Arzobispo era el coordinador general, los obispos responsables directos de la ejecución, y los Vicarios, los inspectores de educación. (Plata, 2001, p. 241)

La Reforma Instruccionista liberal fue vista como un rival a vencer, no sólo a través de las escuelas católicas, sino de la persuasión de los feligreces. En 1872 el obispo Bermúdez lanzó una pastoral prohibiendo a los padres matricular sus hijos en las escuelas liberales so pena de excomunión (Plata, 2001). Adicionalmente, sentenció: "No importa que el país se convierta en ruinas y escombros, con tal que se levante sobre ellas triunfante la bandera de la religión" (Rausch, 1993, p. 117).
La intransigencia religiosa tuvo turbulentos caminos, pues rápidamente se pasó del terreno de las prohibiciones a las acciones bélicas. Se destruyeron las instalaciones de las escuelas liberales, se quemaron los manuales y materiales educativos traídos por la misión alemana. Se persiguió y acosó a maestros y administradores, de forma tal que la confrontación armada fue una consecuencia natural de la fuerte diatriba religiosa, que adquirió con el paso del tiempo la fisonomía de una cruzada religiosa. La respuesta de los gobiernos radicales fue igualmente contundente en el campo discursivo y militar (Ortiz, 2010; Plata, 2001; Rausch, 1993).

\section{Los partidos y sus ideas sobre la formación de la mente humana}

El conflicto político que originó la guerra de las escuelas puso en evidencia un problema de vital importancia. La vida republicana requería una teoría de la mente. Las repúblicas modernas basaban su principio de autoridad y capacidad de gobierno en la buena formación intelectual de los ciudadanos, derivada de la clara comprensión del origen de las ideas y su desarrollo.

El ejercicio de la política, en el mundo moderno, estaba basado en la capacidad de persuadir a la población de que su proyecto estatal era una alternativa válida y legítima, que inspirara respeto, confianza y fidelidad. Se hacía necesario conocer y transigir con las formas de pensamiento de la población. La educación pública debería fundarse en una clara definición del aparato psíquico y la forma de ser estimulado por la labor estatal.

El radicalismo consultó las ideas psicológicas del siglo XIX en un intento por apropiar la ciencia capaz de propiciar el cambio mental, a través de la educación. Manuel Ancízar, administrador de la Reforma Instruccionista, lamentó que la formación de la mente humana en Colombia fuera tratada con base en el sentido común, las pasiones políticas y religiosas, sin mayor fundamentación filosófica y científica:

El estudio de las facultades y fenómenos mentales del hombre es tan delicado y presenta tantas rami- 
ficaciones que no es extraño ver a los talentos más sobresalientes incidir en errores lastimosos cuando han tratado de describirnos cual es la naturaleza del alma, cómo y porqué medios adquiere el hombre sus ideas y cuales son las fuentes del conocimiento. Es condición del entendimiento humano no acertar en toda la verdad de las cosas porque no pudiéndolas estudiar bajo todas sus fases al propio tiempo, necesariamente tiene que irlas considerando en un orden sucesivo, con la lentitud de un detenido análisis. (Ancízar, 1851, p. 4)

Ancízar (1851) consideró que la psicología era la ciencia llamada a mostrar las teorías y debates en torno a la génesis y desarrollo del entendimiento humano. En la psicología se articulaban las filosofías del entendimiento con la explicación científica nacida de la consulta de las actividades orgánicas que hacen posible el ejercicio de las facultades intelectuales (Oviedo, 2010).

El radicalismo había tomado partido al considerar que el origen de las ideas se encontraba en la sensación. El sistema educativo fue considerado un laboratorio de experimentación, en el cual se puso a prueba la incidencia de las visiones sensacionistas en el desarrollo del conocimiento y en el mejoramiento de la calidad de proceso de aprendizaje.

Los radicales asumieron que los colombianos tendrían un cambio de actitud, cuando fueran alfabetizados y entendieran el poder del conocimiento científico y su fuerza transformadora. Los ciudadanos persuadidos de su capacidad de incidir sobre los hechos del mundo material, se convertirían en conocedores de sí mismos y generadores de oportunidades de transformación de su condición personal y social. El conocimiento de la propia mente humana abriría el camino del progreso, haría a las personas más dueñas de sí mismas, y por consiguiente verdaderos orientadores de su libertad. Así, ha sido descrito el estrecho vínculo entre la política y psicología en el siglo XIX:

Según la definición de Andrés Bello, el objeto de la filosofía es el conocimiento del espíritu humano y la acertada dirección de sus actos. Las filosofías del entendimiento parecían cumplir con la función de describir y explicar las operaciones del entendimiento humano, y en seguida, fundamentar mediante, mediante reglas, una dirección de los actos. Vista así la filosofía se reducía a una psicología y una moral (...). Para quienes estaban próximos a asumir la dirección de las jóvenes sociedades de la posindependencia, era urgente adoptar una concepción filosófica que legitimara su existencia (...). A ellas se recurría para legitimar nociones de soberanía, de representatividad política y dominio social. (Loaiza, 2004, p. 80)

La Reforma Instruccionista fue un intento por ligar la doctrina liberal, defensora del individualismo, con las tesis psicológicas sobre el origen sensorial de la conciencia y llevadas a la práctica por medio de la pedagogía pestalozziana. Se esperaba que la educación científica de la población diera por resultado el fomento de la iniciativa industrial, el desarrollo científico-técnico, al igual que el fortalecimiento del intercambio comercial y la dinamización de la participación política.

Entre tanto, los conservadores tuvieron fuertes reparos hacia el proceso secularizador e individualista. Sin embargo, sería erróneo asumir que el conservatismo se opuso a toda forma de progreso. La oposición conservadora se concentró en la defensa de la continuidad histórica de la educación religiosa hispánica, sin renunciar a los ideales del mundo secularizado. Gutiérrez (2000) ha hecho una interesante exposición de la aceptación conservadora de los ideales modernos, pero interpretados dentro del formato del tradicionalismo hispanista:

La aspiración de los conservadores era mantener el poder de la religión y de la familia patriarcal como portadores por excelencia del control social y del principio de autoridad dentro de las nuevas sociedades urbanas que traería el desarrollo del capitalismo en Hispanoamérica. El ideal católico del amor al prójimo y del acatamiento a los mandamientos de Dios y de la Santa Madre Iglesia, debería ser compatible con el ethos capitalista de la máxima utilidad económica, del lucro monetario y de la competencia sin piedad entre propietarios de mercancías (...). (Gutiérrez, 2000, p. 36) 
El pensamiento conservador asumió que la formación de buenos cristianos era la mejor prenda de garantía para la edificación de la ciudadanía, el progreso y la civilización. La educación católica podría dotar a los ciudadanos de sólidas bases intelectuales y morales que harían posible la incorporación de las ideas propias de ciencias como la psicología moderna, sin llegar a desviar el camino de una nación devotamente religiosa.

El país colombiano, al amparo de una educación religiosa, podría mantener su continuidad histórica, sin desarticularse de los desarrollos del mundo moderno, pensaban los conservadores. La educación de la población no debería dar lugar a revoluciones sociales o a cambios dramáticos en las jerarquías y los modos de organización social e individual instaurados por la tradición colonial:

En el fondo el temor de los conservadores era que los tiempos modernos arrasaran con la sociedad agraria tradicional (...). Su exigencia de conservar los valores antiguos de religión e hispanidad, y de convertir la escuela en un bastión de formación religiosa, era para la élite conservadora la garantía de que su mundo y poder no desaparecerían completamente con la llegada de la modernidad. El poder de esta élite tenía su piedra sillar en el principio de que toda autoridad viene de Dios y en que la voluntad divina es el fundamento de toda potestad (...). (Gutiérrez, 2000, pp. 36-37).

El conservatismo asumió una fuerte oposición al liberalismo radical, pues las ideas sensualistas ocultaban una visión mecanicista de la mente humana, sin reconocer su dimensión sobrenatural. Había en los conservadores prevenciones hacia la pérdida de orden y autoridad social con la presencia de las tesis liberales sobre el origen material de las ideas y la dimensión evolucionista del pensamiento. ¿Cómo justificar la existencia de una jerarquía social si su fundamento religioso era supeditado a los intereses de cada individuo? El individualismo liberal fue considerado el caldo de cultivo para el conflicto social, en una sociedad proclive a la violencia armada.

Una población educada con base en la moral católica se mantendría alejada de la condición social de las modernas naciones anglosajonas, caracterizadas por la indolencia, y la lucha entre individuos por sobrevivir. En dichas sociedades industriales se propiciaba la ambición desmedida y la supremacía de los fuertes sobre los débiles, los ricos sobre los pobres, los más educados sobre los ignorantes, sin asomo alguno de la sensibilidad social derivada de la misericordia cristiana.

Si Colombia siguiera el sendero liberal, temían los conservadores, perdería su identidad espiritual de nación caritativa y unida por la confraternidad católica para convertirse en un régimen de producción industrial, regida por la competencia despiadada. Las ideas sensualistas de la psicología deberían compaginarse con la sociedad tradicional, armónica y piadosa, unida por el lazo sagrado de la fe.

La idea conservadora de que la religión sería la plataforma de lanzamiento del país hacia el progreso en el mundo moderno fue ampliamente desarrollada. Años más tarde, bajo los gobiernos del movimiento político de la Regeneración (18781903) se haría posible la consolidación de una psicología católica, inspirada en la filosofía de Santo Tomás. El movimiento neotomista en alianza con la Regeneración procuró recuperar el ancestral objeto de estudio de la psicología, el alma humana, acordemente con la tradición aristotélico-tomista (Oviedo, 2009, 2012a, 2012b).

La guerra de las escuelas fue un campanazo de alerta que obligó al pensamiento tradicionalista, propio del clero y los conservadores, a desarrollar una propuesta católica para la formación de la mente. Tras la finalización de la guerra en 1877 , hubo un consenso en las huestes conservadoras y católicas colombianas: había que perfilar un modelo de formación espiritual que tomara el vino nuevo de la psicología moderna y la madurara en el odre viejo del catolicismo. Las palabras del cardenal Mercier en 1891, uno de los más importantes representantes del neotomismo en la Universidad Lovaina, tuvieron un eco resonante en el tradicionalismo colombiano:

La psicología pasa hoy por una transformación que seríamos culpables si permaneciéramos alejados de ella (...). Aquí una joven ciencia contemporánea, 
la cual en sí misma no es espiritualista, ni materialista. Sino tomamos parte en ella, la psicología del futuro progresará sin nosotros, y toda la razón induce a creer, contra nosotros. (Misiak \& Staudt, 1955, p. 50)

\section{Conclusiones}

En la década de 1870, mientras se fundaba la psicología experimental alemana, Colombia se encontraba en medio de una batalla ideológica y militar en torno a la formación espiritual de la nación. La guerra de las escuelas de 1876 fue el camino corto que recorrió el país para decidir el formato estatal que permitiría dotar a la población de una conciencia individual, juicio crítico independiente y el ejercicio de la ciudadanía.

La psicología experimental, la ciencia de la conciencia, fue consultada por los partidos políticos para definir la conveniencia de educar la población con base en sus proposiciones científicas. El liberalismo acogió la tesis psicológica del origen sensorial de la conciencia e intentó llevarla a la práctica educativa, a través de la aplicación del método pestalozziano.

El conservatismo y el clero presentaron sus reparos frente a la consideración de la sensación como el determinante único de la conciencia, por considerarlo una postura impía, en el que se desconocía a Dios creador del ser humano y sus facultades mentales. La tradición católica, desde el pasado colonial, había mostrado mayor eficiencia educativa que las ciencias modernas, en la formación de la personalidad histórica de la nación. La población colombiana profesaba la fe cristiana y encontraba en ella su lazo natural para encontrar el orden social. El conservatismo veía con preocupación la tendencia a sustituir repentinamente siglos enteros de edificación de las creencias populares para introducir ideologías ajenas y distantes al sentir de la población.

El debate bipartidista se focalizó de manera exclusiva en el protagonismo de la sensación en la constitución de la conciencia, hecho que llevó a los partidos a dejar de lado otros componentes de gran importancia desarrollados por la psicología experimental, como la tesis del asociacionismo. Las interpretaciones sobre la génesis de la conciencia con la presencia de Dios o en su ausencia hicieron difícil seguir el discurso sobre el transcurso de la experiencia sensorial dentro de los estados subjetivos.

\section{Referencias}

Ancízar, M. (1851). Lecciones de psicología. Bogotá: Ediciones del Neo-granadino.

Ardila, R. (1973). La psicología en Colombia: desarrollo histórico. México: Trillas.

Arboleda, S. (1972). La república en la América Española. Bogotá: Biblioteca Banco Popular. (Original publicado en 1869)

Boring, E. (1996). Historia de la psicología experimental. México: Trillas. (Original publicado en 1929)

Briceño, M. (1947). La revolución (1876-1877). Bogotá: Imprenta Nacional. (Original publicado en 1878)

Carrasquilla, R. M. (1961). Sobre el estudio de la filosofía. En Obras completas (Tomo III, Vol. 1). Bogotá: Imprenta Nacional. (Original publicado en 1881)

Clawsewitz, C. (2005) De la guerra. Madrid: La esfera de los libros (Original publicado en 1832)

García del Río, J. (1985). Meditaciones colombianas. Bogotá: Incunables. (Original publicado en 1829)

Gutiérrez, E. (2000). La política instruccionista de los radicales intento fallido de modernización en Colombia en el siglo XIX (1870-1880). Bogotá: Fomcultura, Gobernación del Huila.

Guzmán. C. (1883) Filosofía experimental. Bogotá: Imprenta Medardo Rivas.

Jaramillo, J. (2001). El pensamiento colombiano en el siglo XIX. Bogotá: CESO, Uniandes, Banco de la República, Icanh, Conciencias, Alfaomega. (Original publicado en 1956)

Loaiza, G. (2004). Manuel Ancízar y su época. Biografía de un político hispanoamericano en el siglo XIX. Medellín: Editorial Universidad de Antioquia, Fondo Editorial Universidad Eafit.

Martínez, F. (2001). El nacionalismo cosmopolita. La referencia europea en la construcción nacional en Colombia, 1845-1900. Bogotá: Banco de la República, Instituto Francés de Estudios Andinos. 
Meyer Loy, J. (1977). La educación primaria durante el federalismo: la reforma escolar de 1870. Revista Colombiana de Educación, 3, 1-15.

Misiak, H., \& Staudt, V. (1955). Los católicos y la psicología. Anotaciones históricas. Barcelona: Juan Flors.

Núñez, R. (1946). La reforma política (Vol. 6). Bogotá: Editorial ABC. (Original publicado en 1891)

Ortiz, L. J. (2010). Obispos, clérigos y fieles en pie de guerra. Antioquia, 1870-1880. Medellín: Editorial Universidad de Antioquia, Universidad Nacional de Colombia.

Oviedo, G. L. (2009). Concepciones psicológicas colombianas en el siglo XIX. Revista de Historia de la Psicología, 30(4), 7-32.

Oviedo, G. L. (2010). Lecciones de psicología - Colombia siglo XIX. Revista Avances en Psicología Latinoamericana, 28(2), 278-293.

Oviedo, G. L. (2012a). La conciencia psicológica en Colombia y Alemania. El conflicto científico de la psicología en un país católico. Saarbrücken, Alemania: Editorial Académica Española.

Oviedo, G. L. (2012b). Colombian approaches to psychology in the 19th. Century. History of Psycho$\log y, 15(4), 291-301$.

Peña, T. E. (1993). La psicología en Colombia: historia de una disciplina y una profesión. En Historia social de la ciencia en Colombia. Ciencias sociales (Vol. 9). Bogotá: Colciencias.

Pestalozzi, J. E. (1967). Cómo Gertrudis educa a sus hijos. Buenos Aires: Centro Editor de América Latina, Letra Firme. (Trabajo original publicado en 1826)

Plata, W. E. (2001). El catolicismo y sus corrientes en Colombia decimonónica 1850-1880 (Tesis de maestría no publicada). Universidad Nacional de Colombia, Bogotá.

Rausch, J. (1993). La educación durante el federalismo. La reforma escolar de 1870. Bogotá: Instituto Caro y Cuervo, Universidad Pedagógica Nacional.

Sáenz, J., Saldarriaga, O., \& Ospina, A. (1997). Mirar la infancia: pedagogía, moral y modernidad en Colombia, 1903-1946 (Vol. 1). Bogotá: Colciencias, Foro Nacional por Colombia, Uniandes, Universidad de Antioquia/Clío.

Saldarriaga, O. (1997). La apropiación de la pedagogía pestalozziana en Colombia (1845-1930). En A. Navarro \& J. A. García (Comps.), La recepción de la pedagogía pestalozziana en las sociedades latinas. Madrid: Megazul-Endymion.

Zuluaga, O. L. (2001). Entre Lancaster y Pestalozzi: los manuales para la formación de maestros en Colombia, 1822-1868. Revista Educación y Pedagogía, 13(29-30), 41-49. 
